\title{
CRAYON SHARKS: UM ESTUDO DE CASO SOBRE O DESIGN E APLICAÇÃO DE UM JOGO DIGITAL PARA O ENSINO DE CIÊNCIAS
}

\author{
M. L. M. SILVA ${ }^{*}$ e R. M. de ARAUJO \\ Instituto Federal de Educação, Ciência e Tecnologia do Rio Grande do Norte \\ marcos.martins@ifrn.edu.br
}

Submetido 05/04/2015 - Aceito 10/10/2017

DOI: $10.15628 /$ holos.2017.3080

\section{RESUMO}

As metodologias utilizadas para o ensino de ciências têm variado bastante nas últimas décadas principalmente em função das mudanças que ocorreram na sociedade e, portanto, nas escolas. Levando em consideração a realidade do mercado de jogos digitais e a disseminação de novas tecnologias entre os jovens de hoje em dia, podemos constatar o impacto que o uso casual dessas novas mídias possuem dentro da sala de aula. Esse cenário caracteriza uma nova oportunidade para a promoção do engajamento e envolvimento dos alunos caso o professor insira jogos digitais dentro do processo educativo formal. O presente trabalho traz uma discussão sobre a relevância da utilização de jogos digitais em sala de aula e fundamenta a atuação do
\end{abstract}

professor nos processos de design e aplicação de jogos digitais. Descreve, ainda, as etapas do desenvolvimento e aplicação do protótipo de um jogo digital educativo voltado para o ensino de ciências numa turma de 70 ano do ensino fundamental de uma escola da rede pública de ensino do município de Macau/RN. Como resultado, a partir da análise das respostas dos questionários e da observação das reações dos alunos durante a dinâmica de aplicação do jogo digital, foi possível constatar a aceitação da proposta por todos os alunos participantes. O jogo foi caracterizado como uma experiência divertida, que facilita ou estimula o aprendizado, e auxilia a compreensão dos conceitos relacionados à disciplina de Ciências de uma maneira mais atrativa.

PALAVRAS-CHAVE: Ensino de Ciências, Jogos Digitais, Aprendizagem Significativa.

\section{CRAYON SHARKS: A CASE STUDY ON THE DESIGN AND APPLICATION OF A DIGITAL GAME FOR SCIENCE TEACHING}

\begin{abstract}
The methodologies used for science teaching have varied widely in recent decades mainly due to the changes that have occurred in society and therefore in schools. Taking into account the reality of the digital games market and the dissemination of new technologies among young people nowadays, we can verify the impact that the casual use of these new media have in the classroom. This scenario features a new opportunity to promote the engagement and involvement of students In case the teacher insert digital games within the formal educational process to present lessons with different methodologies and using a technology that is part of the social context of students. This work presents an argument about the relevance of the use of digital games in the classroom and theorizes
\end{abstract}

the teacher performance on design processes and application of educational games. It also describes the stages of development and application of a prototype of a digital educational game focused on science teaching in a class of 7th grade of an elementary school on a public school in the city of Macau/RN. As a result, based on the analysis of questionnaires responses and on the observation of the students' reactions during the applying dynamic of the digital game, it was possible to verify the acceptance of the proposal by all the participant students. The game was characterized as a fun experience that facilitates or encourages learning and helps the understanding of concepts related to the discipline of Science in a more attractive way.

KEYWORDS: Science Teaching, Digital Games, Meaningful Learning. 


\section{INTRODUÇÃO}

O impacto cultural dos jogos digitais tem crescido, rivalizando a televisão e filmes enquanto a indústria tem amadurecido ao longo das últimas três décadas (FULLERTON, 2008). No Brasil, desde o ano de dois mil e dez tem sido possível perceber o quanto os jogos digitais têm se tornado cada vez mais presentes no cotidiano dos jovens, especialmente em virtude da popularização dos smartphones e de outros aparelhos portáteis de maior capacidade de processamento. A recente explosão de jogos casuais e facilmente disponíveis para download adicionou mais complexidade ao diverso mundo dos videogames comerciais (GREGORY, 2009).

Atualmente, o mercado para pequenos desenvolvedores de jogos digitais encontra-se aberto e, de certa forma, estimulado. É nesse cenário que se prolifera o segmento de jogos independentes, ou seja, jogos de baixo custo desenvolvidos por pequenas empresas. Cada vez mais esse segmento tem conseguido conquistar espaço entre as grandes empresas do mercado. Mas, na verdade, o que faz desses jogos um sucesso de público? Qual o atrativo que eles podem apresentar se comparados com os de grandes desenvolvedoras, com orçamentos alcançando o patamar da indústria cinematográfica? Para responder essas questões é necessário considerar dois fatores norteadores no desenvolvimento de jogos: público alvo e proposta. A maioria dos jogos independentes que fazem sucesso na atualidade se baseiam, essencialmente, numa ideia simples, porém, significativa.

As metodologias utilizadas para o ensino de ciências têm variado bastante nas últimas décadas principalmente em função das mudanças que ocorreram na sociedade e, portanto, nas escolas. Levando em consideração a realidade do mercado de jogos digitais e a disseminação de novas tecnologias entre os jovens de hoje em dia, podemos constatar o impacto que o uso casual dessas novas mídias possuem dentro da sala de aula. Esse cenário, considerado "adverso" por grande parte dos profissionais da educação, caracteriza uma nova oportunidade para a promoção do engajamento e envolvimento dos alunos caso o professor insira jogos digitais dentro do processo educativo formal ao apresentar uma aula com metodologias variadas e com o uso de uma tecnologia que faz parte do contexto social dos alunos.

O presente trabalho traz uma discussão sobre a relevância da utilização de jogos digitais em sala de aula e fundamenta a atuação do professor nos processos de design e aplicação; descreve as etapas do desenvolvimento e aplicação do protótipo de um jogo digital educativo voltado para o ensino de Ciências numa turma de 70 ano do ensino fundamental de uma escola da rede pública de ensino do município de Macau/RN, além de expor os resultados alcançados.

\section{DESIGN E APLICAÇÃO DE JOGOS DIGITAIS NA EDUCAÇÃO: COMO E POR QUE?}

\subsection{O jogo digital na sala de aula: engajamento e motivação}

Todo jogo é lúdico em sua essência, se reserva ao ato de brincar. É dentro do conceito do lúdico, na educação, que estão incluídos os jogos, os brinquedos e divertimentos advindos da prática. Huizinga (2000) afirma que no ato de jogar "existe alguma coisa 'em jogo' que transcende as necessidades imediatas da vida e confere um sentido à ação", enfatizando a importância dos jogos e classificando-os como um elemento cultural, que independe da idade. 


\begin{abstract}
“O jogo, nas suas diversas formas, auxilia no processo ensino-aprendizagem (...) no desenvolvimento de habilidades do pensamento, como a imaginação, a interpretação, a tomada de decisão, a criatividade, o levantamento de hipóteses, a obtenção e organização de dados e a aplicação dos fatos e dos princípios a novas situações que, por sua vez, acontecem quando jogamos, quando obedecemos a regras, quando vivenciamos conflitos numa competição, etc." (CAMPOS, 2006 apud MAURÍCIO, 2014)
\end{abstract}

Durante uma partida de um determinado jogo, o jogador apresenta, habitualmente, persistência, disposição a correr riscos, atenção aos detalhes, além de desenvolver habilidades para resolver os problemas impostos, todos os comportamentos que idealmente se espera que eles demonstrem na escola (KLOPFER, OSTERWEIL e SALEN, 2009).

\begin{abstract}
"O mundo do adulto é intrinsecamente diferente do mundo da criança. O mundo adulto é utilitário, produtivo, realista. O mundo da criança é lúdico, fantástico, idealista (...). O adulto produz e aprende trabalhando, a criança brincando. $\mathrm{O}$ trabalho e o aprendizado da criança acontecem brincando. É através disto que a criança vai tomando contato com o mundo das regras. Todo o jogo tem suas regras que devem ser entendidas, incorporadas e respeitadas pela criança." (FREIRE e SHOR, 1987, p. 74)
\end{abstract}

Roger Pendersen (2003) explica que jogos digitais do gênero educativo possuem ênfase nos processos de ensino-aprendizagem, ou seja, o processo de design se concentra no ensino e/ou reforço de conceitos a serem apreendidos pelo aluno em um determinado momento da aula. Apesar de alguns jogos educativos parecerem outros gêneros de jogos, eles não o são simplesmente por enfatizarem a educação em seus processos de desenvolvimento. Levando isso em consideração, é possível perceber que o fator que determina se um jogo é ou não educativo é simplesmente a sua proposta, o seu fim.

O jogo digital educativo atua, então, como uma ferramenta onde se pode experimentar diversas ações e se analisar os resultados advindos delas, provocando a atividade intelectual e desenvolvendo as capacidades cognitivas do jogador. Esse potencial que os jogos digitais possuem pode ser amplificado ainda mais se considerarmos que a escola, hoje em dia, prioriza o aprendizado de "fatos" antes de estimular a capacidade de "resolução de problemas".

"Uma das qualidades mais atraentes da tecnologia digital é que ela pode oferecer um feedback imediato e interativo. Sistemas de ações e resultados, onde o jogo responde perfeitamente às ações de entrada do jogador, são elementos comuns em jogos digitais. A tecnologia digital oferece, assim, o jogo em tempo real, que muda e reage dinamicamente às decisões do jogador." (SALEN e ZIMMERMAN, 2004, p. 87)

Para tanto, é necessário que o jogador utilize as informações e fatos à sua disposição como ferramentas para a resolução desses problemas, viabilizando a apreensão do conteúdo e estimulando sua capacidade cognitiva. Então, a motivação principal que move o jogador a tentar resolver esses problemas está intrinsecamente relacionada à sensação de "realização" após o cumprimento de cada etapa do jogo.

Uma premissa importante que impulsiona essa "realização" é a de que, nos níveis iniciais do jogo, os desafios sejam impostos para preparar o jogador para os níveis mais difíceis adiante. Essa ideia de dividir os problemas em níveis de complexidade, ou seja, a adequada ordenação 
desses problemas é, consequentemente, um excelente caminho para uma aprendizagem significativa (GEE, 2004).

Esse elemento é muito bem descrito por Jane McGonigal (2011) ao afirmar que os jogos digitais se utilizam de recursos para manter o jogador motivado, com um elevado grau de otimismo e com o baixo índice de frustração, integrando a narrativa e o sistema de regras para que o jogador explore o ambiente de jogo, de uma maneira que seja sempre possível completar determinada missão, mas com um grau de dificuldade alto o suficiente para manter a motivação do jogador.

Em certos gêneros de jogos que não possuem essa divisão em níveis de dificuldade, o próprio gameplay é planejado para criar esse elemento de desafio, fazendo com que o jogador tenha que se adaptar às mecânicas do jogo para conseguir resultados melhores a cada partida.

\subsection{O professor como game designer: reflexos e possibilidades}

Os jogos são uma parte integrante de todas as culturas humanas conhecidas. Os jogos digitais, em todos os seus vários formatos e gêneros, são apenas uma nova expressão desse antigo método de interação social (FULLERTON, 2008). Guilherme Xavier (2010) afirma que o jogo digital é atualmente o pilar de uma estrutura cultural e simbólica maior, que envolve não apenas especialistas em suas conceituação e construção, mas toda sorte de indivíduos prontos a participar da disseminação de um potente modelo tecnológico, como autores e atores.

O trabalho realizado por um game designer é o de visionar como um jogo vai funcionar durante uma partida, criando os objetivos, as regras e procedimentos, pensando na premissa dramática, dando vida ao jogo, planejando o necessário para criar uma experiência engajante para o jogador (FULLERTON, 2008). Numa comparação livre entre o trabalho de um game designer e o de um professor, conceitualmente, podemos perceber várias semelhanças. Ambos precisam considerar o design de experiências como foco no planejamento de suas atividades principais. Nenhum desses profissionais conseguirá alcançar os objetivos propostos, seja numa etapa de concepção de um jogo ou na preparação de um plano de aula, se não levarem em consideração seu público alvo. Atualmente, tanto o professor quanto o game designer se valem de mídias digitais para a execução de suas propostas.

Uma aula não pode se valer apenas de uma metodologia repetida incansavelmente durante todo um período letivo. Da mesma forma, jogos digitais que utilizam fórmulas antigas, sem nenhuma inovação, tendem a fracassar por não despertarem o interesse em seu público. 0 professor, assim como o game designer, precisa se colocar no lugar do público, os alunos, e se perguntar se o seu planejamento apresenta características atrativas, que vão prender a atenção deles durante uma experiência proposta.

Consideradas essas semelhanças e reconhecendo as diferenças, por que, então, existe um vácuo que distancia tanto essas duas profissões? Esse anacrônico paradigma vem pouco a pouco sendo quebrado porque as grandes empresas da indústria de games e as pequenas desenvolvedoras independentes já possuem o conhecimento de que uma equipe para a criação de jogos digitais precisa ser multidisciplinar, com profissionais de diversas áreas e que possuam o interesse específico em participar do processo de design, envolvendo-se nas diversas etapas como o planejamento do gameplay, o desenho das artes, a concepção das narrativas e inserção de conteúdo, a programação do sistema, a área comercial, etc. 
O design de jogos já deixou de ser algo exclusivo para programadores que tinham o código (a linguagem de programação) como ferramenta principal e espinha dorsal de um jogo digital. Há alguns anos ferramentas denominadas game engines têm sido criadas dentro das próprias desenvolvedoras para simplificar e abstrair a entrada dos códigos, possibilitando a participação direta de outros profissionais envolvidos nos processos de design. Atualmente algumas desenvolvedoras se especializaram na criação e aprimoramento dessas ferramentas, distribuindo-as na internet para qualquer pessoa que deseje ingressar no segmento de jogos digitais ou até mesmo equipes e empresas que necessitem simplificar seu processo de desenvolvimento. A maioria dessas ferramentas encontram-se disponíveis gratuitamente, com limitações no uso e na distribuição, ou através da aquisição de licenças pagas, com uso ilimitado e gerenciamento dos jogos publicados.

Nessa perspectiva, com todas as ferramentas e possibilidades existentes, o professor também pode atuar como um articulador do processo de design de jogos digitais voltados para a educação, respeitando-se suas limitações e explorando-se suas aptidões, orientando o design para atingir determinados fins, fazendo com que o jogo seja pensado dentro de um processo educativo formal.

\subsection{O professor, o jogo digital e o uso de narrativas: contando histórias}

O professor, ao intermediar o uso de jogos digitais educativos em sala de aula, precisa ter cautela e competência no planejamento para que não se perca a dimensão lúdica, fazendo com que o jogo esteja integrado à aula proposta, transformando a construção de conhecimentos numa experiência compartilhada e engajante.

Para tanto, o jogo não pode virar obrigação ou ser usado com finalidade de instrução apenas, ou ele perde seu caráter de espontaneidade e deixa de ser jogo porque seu potencial de exploração e invenção é esvaziado (CAMPOS, 2014), facilitando a desconstrução da ideia do "estado de bem-estar" da ludicidade, proposta por Freinet (1998), ou seja, uma atividade, a princípio pensada como instigante aos alunos, pode, se mal planejada, se tornar uma experiência cansativa e desestimulante.

Por este motivo, a aplicação de um jogo digital educativo, seja ele completo ou ainda um protótipo, deve ser pensada de maneira a conciliar a metodologia de uma aula expositiva e dialogada com a interação dos alunos com o jogo digital mediada através de uma dinâmica em grupo, regida através de uma narrativa. Murray (2003) afirma que "uma narrativa excitante, em qualquer meio, pode ser experimentada como uma realidade virtual porque nossos cérebros estão programados para sintonizarmos histórias com uma intensidade que pode obliterar o mundo à nossa volta".

Costikyan (2002) afirma que, em alguns casos, os jogos podem complementar uma determinada narrativa, porque eles permitem que você explore um sistema para experimentar alternativas, enquanto uma narrativa linear se atém aos eventos literais e não as possibilidades.

"Todo jogo se processa e existe no interior de um campo previamente delimitado, de maneira material ou imaginária, deliberada ou espontânea (...) a arena, a mesa de jogo, o círculo mágico, o templo, o palco, a tela, o campo de tênis, o tribunal etc., têm todos a forma e a função de terrenos de jogo, isto é, lugares proibidos, isolados, fechados, sagrados, em cujo interior se respeitam 
determinadas regras. Todos eles são mundos temporários dentro do mundo habitual, dedicados à prática de uma atividade especial." (HUIZINGA, 2000, p. 13).

A ideia de que essas experiências estão, de alguma maneira, separadas de outras experiências por limites, fronteiras, é outra característica semelhante à estrutura dos jogos (FULLERTON, 2008). Murray (2003, p. 117) explica que "compartilhar um ambiente de fantasia improvisado com outras pessoas envolve uma negociação constante do enredo e também dos limites entre a ilusão consensual e o mundo real".

A estrutura de linguagem utilizada num jogo digital remete à metáfora de "rizoma", proposta por Deleuze e Guattari (1995) porque ela se distancia da linearidade inerente a narrativas escritas, a história vai sendo construída de acordo com as ações do jogador quando ele interage com o sistema de jogo e os diversos resultados obtidos, inicialmente ocultos, são desvelados progressivamente a partir de suas decisões.

Com isso em mente, o professor poderá atuar como a figura de um "contador de histórias", convidando os alunos ao jogo, estabelecendo um círculo mágico, conduzindo a narrativa durante uma aula, complementando a experiência do aluno e o transformando em um sujeito agenciador, um sujeito que dialoga, que interage com as imagens, com sons e com estímulos táteis (MACHADO, 2007).

\section{FUNDAMENTAÇÃO E MEIOS PARA O PROCESSO CRIATIVO}

\subsection{Saberes essenciais: design, gameplay, interatividade e significação}

Greg Costikyan (1994), em seu artigo "I Have No Words \& I Must Design", concebe o jogo como "uma forma de arte na qual participantes, denominados jogadores, tomam decisões a fim de gerenciar recursos utilizando-se de símbolos de jogo na busca de um objetivo". Esse conceito deixa implícitas três ideias: o jogo, enquanto forma de arte, é fruto do design de algum agente, que projeta uma experiência a ser vivenciada pelo jogador; a interatividade é um elemento intrínseco em um jogo, o qual perde sua função sem ela; e o jogo precisa ter algum objetivo, algum significado.

O conceito de design pode ter uma infinidade de definições de acordo com o contexto a ser aplicado. Considerando o teor do presente trabalho, esse conceito foi situado dentro do tema dos jogos digitais e os processos envolvidos no seu desenvolvimento. Katie Salen e Eric Zimmerman (2004) definem design como o processo pelo qual um designer cria um contexto a ser encontrado por um participante, do qual a significação emerge, caracterizando o designer como o indivíduo ou grupo por trás da criação do jogo; o contexto como o conjunto de espaços, objetos, narrativas e comportamentos; e a significação como resultado da interação do participante com o jogo.

A interatividade intrínseca aos jogos digitais descreve um relacionamento ativo entre duas coisas, quando pessoas podem participar como agentes dentro de um contexto de representação, ou seja, deve haver reciprocidade entre dois elementos de um sistema (SALEN e ZIMMERMAN, 2004). Chris Crawford (2013) aprofunda esse conceito e o torna mais geral, permitindo múltiplas interpretações, definindo a interatividade como um processo cíclico entre 
dois ou mais agentes ativos, no qual dois atores ouvem, pensam e falam, alternadamente. Essa afirmação apresenta os termos ouvir, pensar e falar de maneira geral e metafórica, podendo, em linguagem computacional serem substituídos pelos termos entrada, na qual o jogador aciona uma tecla ou um botão (ou toca em uma tela); processamento, onde a informação de entrada é processada pelo computador ou console; e saída, onde o resultado do processamento da ação é apresentado numa tela em pixels.

Xavier (2010) explica que o jogo digital tem como mote permitir que a estrutura lúdica nele manifestada seja alterada pela retroalimentação configurativa de um ou mais indivíduos operadores. A elaboração cuidadosa da experiência do jogador através de um sistema de interação é fundamental para a concepção de um jogo significativo. Salen e Zimmerman (2004) explicam que significação, divertimento e jogo são conceitos intimamente relacionados, o que leva à conclusão que o objetivo de todo o design de jogos deve ser uma interação lúdica significativa. Essa interação lúdica é justamente o ato de jogar, o play, quando o jogador interage com o jogo através de ações (decisões) que resultarão em respostas, transmitidas através de símbolos de jogos. A interpretação que o jogador terá dessa interação lúdica será a significação.

A interatividade está intimamente ligada aos conceitos de design, sistemas e significação. Quando um jogador interage com o jogo desenvolvido, a significação emerge. As muitas definições para interatividade consideram diversos modos de manifestação: a interatividade cognitiva, a interatividade funcional, a interatividade explícita ou a participação cultural (SALEN e ZIMMERMAN, 2004). Essas quatro formas de manifestação não sobrepõem umas às outras, elas ocorrem simultaneamente em qualquer experiência de um sistema projetado.

Esse sistema projetado se refere ao gameplay, do qual a experiência que o jogador vivencia ao utilizar o jogo faz parte. Esse termo é geralmente concentrado dentro dos elementos dinâmicos de um jogo, por isso o termo game mechanics (mecânicas de jogo) define essa ideia de uma maneira um pouco mais concreta - é usualmente definida como o conjunto de regras que comandam as interações entre as várias entidades no jogo (GREGORY, 2009). Patrick O'Luanaigh (2005) descreve o gameplay como um conjunto de mecânicas de jogo que são responsáveis pelos aspectos fundamentais da atividade do jogador dentro deste jogo. Essa relação entre o jogador e o jogo é o que vai fazer com que ele dedique grande parte do seu tempo à essa atividade, por diversas vezes, até que seja alcançado um determinado objetivo. A significação resultará das experiências criadas pelo designer, porém, o designer não pode se apropriar das experiências do participante e nem as manipular diretamente (SCHELL, 2008), o que efetivamente pode ser feito para este fim é a moldagem do jogo em si.

\subsection{Game engines: simplificando o desenvolvimento}

Desenvolver um jogo digital não é uma tarefa simples. Montar visuais, movimentações, animações e interações a partir de códigos consiste realmente num fator limitante para quem possui ideias mas não possui domínio em linguagens de programação. Considerando a grande variedade de estilos de jogos e a diversidade de plataformas, é fácil constatar que não existe uma solução única de software ideal, no entanto, certos padrões se desenvolveram, e há um vasto cardápio de possíveis soluções no mercado. Hoje, o problema é escolher a solução certa para atender às necessidades de um projeto em particular (GREGORY, 2009). 
Para diminuir a distância entre a ideia e a execução de determinado projeto, existem ferramentas que auxiliam todo o processo de design, são os game engines, os motores de jogos. Um game engine é um conjunto de bibliotecas de dados, um pacote de funcionalidades, que simplificam e abstraem a entrada dos códigos necessários ao desenvolvimento de jogos digitais, evitando que a criação tenha que ser feita do zero e virtualizando o resultado do processo de programação em gráficos em tempo real (KLEINA, 2011). Ultimamente, com cada vez mais ferramentas desse tipo disponíveis e espaços de divulgação, o design e a distribuição de games deixou de ser privilégio apenas de grandes empresas para se transformar em uma opção aberta para qualquer pessoa que queira se empenhar em um projeto de jogo (NEMES, 2012). Os game engines contém um conjunto familiar de componentes centrais, incluindo o motor de renderização, o motor de colisão e física, o sistema de animação, o sistema de áudio, o modelo de objeto do mundo do jogo, o sistema de inteligência artificial, e assim por diante (GREGORY, 2009).

A maioria dos game engines disponíveis no mercado, por natureza, ainda demandam conhecimentos avançados sobre determinadas linguagens de programação (Java Script, C, C++, $\mathrm{C \# ,} \mathrm{etc.),} \mathrm{mesmo} \mathrm{assim,} \mathrm{existem} \mathrm{alguns} \mathrm{que} \mathrm{conseguem} \mathrm{abstrair} \mathrm{completamente} \mathrm{o} \mathrm{processo} \mathrm{de}$ inserção de códigos através de uma seção que se utiliza apenas da lógica de programação, acessível a um público mais amplo no qual o professor está incluído. Por este motivo, para o desenvolvimento do protótipo proposto no presente trabalho, foram escolhidos o Flowlab e o Construct 2.

\section{METOdOLOGIAS UTILIZADAS NOS PROCESSOS DE DESENVOLVIMENTO E APLICAÇÃO DO PROTÓTIPO “CRAYON SHARKS”}

\subsection{Concepção, design e prototipagem}

A organização do processo de design é imprescindível para que, ao se obter o produto final, este não venha a interromper ou atrapalhar a experiência do jogador. Visando favorecer a viabilidade de um determinado projeto e a obtenção de resultados satisfatórios com o produto final, Fullerton (2008) orienta a organização do processo de design do jogo digital através da metodologia do design iterativo, que divide todo o processo criativo em etapas, seguindo um procedimento cíclico de prototipagem, testes, análise e refinamento do projeto em desenvolvimento.

Seguindo as orientações dessa metodologia, o primeiro passo foi a definição do tema a ser abordado no jogo. Estabelecendo o ensino de Ciências como linha central no desenvolvimento do presente trabalho, optou-se pelo tema Ecologia, por ser suficientemente abrangente, e extremamente relevante aos demais conteúdos relacionados à Biologia. $\mathrm{O}$ passo seguinte foi a definição do público alvo: alunos de turmas de 70 ano do ensino fundamental da rede pública, com faixa etária entre 11 (onze) e 13 (treze) anos. Essa escolha se deu em virtude da distribuição do conteúdo programático da disciplina de Ciências nas escolas do município, no qual o conteúdo Ecologia é introduzido no 6으 ano do ensino fundamental e aprofundado no 7으 ano.

Como objetivos de aprendizagem, foram priorizados assuntos relacionados ao tema que tivessem bons resultados com o uso de uma mecânica simples, como a adaptação das espécies 
ao seu ambiente, a relação entre presa e predador, o conceito de biodiversidade, a seleção natural e as cadeias e teias alimentares. A premissa básica do jogo foi pensada de uma maneira que o jogador assumisse o papel de um jovem tubarão, que precisa se alimentar, se proteger de predadores e se reproduzir, deixando descendentes.

Objetivando alcançar o estado de pré-visualização previsto nesta etapa do design, foi convidada para desenvolver as artes conceituais do jogo a artista Maria Eduarda Silva dos Santos, aluna do 20 ano do Curso Técnico Integrado em Química do IFRN - Campus Macau, pelo seu conhecido talento no desenho de animais e paisagens naturais. Os desenhos foram feitos por ela com o uso lápis de cor e foram pintados com giz de cera e, por este motivo, o protótipo foi denominado "Crayon Sharks". O título em inglês foi pensado para despertar a curiosidade dos alunos e manter uma proposta comercial para uma versão final do jogo.

O Flowlab foi inicialmente utilizado para testar as mecânicas de jogo preteridas para o protótipo, porém, para o processo de design em si, o game engine escolhido foi o Construct 2, por permitir uma maior liberdade no processo de inserção de imagens e por não necessitar de conexão com a internet para o design e posterior utilização do produto final.

A mecânica básica do jogo foi montada com a intenção de integrar a narrativa ao gameplay, sendo inseridas duas espécies de peixes, uma que se alimenta de macroalgas e uma que se alimenta de corais, dispostos sobre a lâmina d'água, e o tubarão, representado pelo avatar $^{1}$, com a movimentação realizada pelo jogador através das teclas direcionais do teclado. A cada partida, o avatar do jogador precisará evitar os predadores e se alimentar de 15 (quinze) peixes, independente da espécie. O resultado de cada campanha será diferente de acordo com o "cardápio" do tubarão, mantendo ou não o equilíbrio do ecossistema, de maneira a demonstrar a importância de cada animal em suas relações na teia alimentar.

O gameplay foi pensado de uma maneira que, além de proporcionar uma experiência individual para o jogador, ele também possa ser aplicado coletivamente em sala de aula, fazendo com que todos os demais alunos visualizem a experiência do jogador, propiciando uma construção de conhecimentos coletiva. Considerando que a etapa da prototipagem, parte fundamental da etapa do design, deve consistir na reunião das ideias de uma maneira jogável, realizada de forma rápida, para avaliar os possíveis resultados de uma versão final, foi planejado que o protótipo fosse montado, ainda, com as mecânicas chaves do jogo para que se pudesse saber se os jogadores a achariam interessante. Portanto, durante o processo de design, foi preparado o protótipo do jogo digital, unindo as artes conceituais às mecânicas já implementadas.

\footnotetext{
${ }^{1}$ Representação gráfica escolhida por um usuário - ou desenvolvida por um designer - para representar o jogador em determinados jogos ou em comunidades virtuais (MURRAY, 2003).
} 


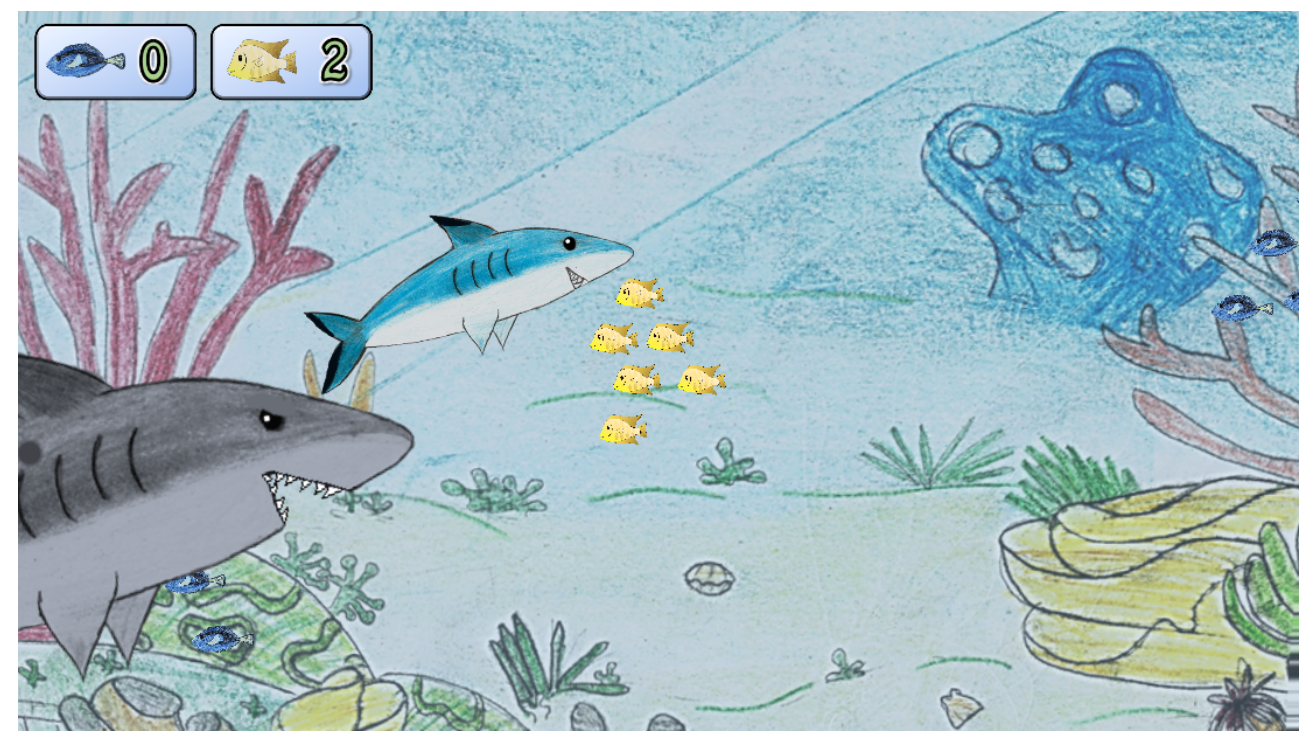

Figura 1: Screenshot demonstrando o gameplay e a interface do protótipo.

Foram montadas, de maneira rápida, as telas de resultados, com uma narrativa explicativa, esclarecendo cada resultado das interações do aluno-jogador dentro do jogo. A parte textual do jogo foi inserida na língua portuguesa e na língua inglesa, aperfeiçoando o caráter interdisciplinar do protótipo e tornando o processo de aplicação um pouco mais desafiador e instigante. Outro fator importante inserido foi uma interface gráfica, com botões e contadores, para que o usuário possa navegar através dos layouts do jogo e verificar seu progresso e seu resultado.

Para composição da paisagem sonora do protótipo foram utilizadas trilhas disponíveis gratuitamente no site "IndieGameMusic" (disponível em: <http://indiegamemusic.com/>) e os efeitos sonoros foram criados com a utilização da ferramenta "as3sfxr" (disponível em: <http://www.superflashbros.net/as3sfxr/>).

Com o protótipo finalizado, foi preparado um questionário semiestruturado para avaliar a experiência de cada aluno, com 03 (três) perguntas simples e 01 (um) depoimento sucinto, cujo resultado serviu de subsídios para a discussão apresentada no item 5 . Além disso, ciente de que não se pode fazer design simplesmente a partir de estatísticas, examinar o feedback dos alunos durante a aplicação consistiu em um excelente subsídio complementar à aplicação dos questionários, verificando se a experiência proporcionada pelo jogo digital seria engajante, se haveria um real interesse na utilização de uma versão final do jogo e se existiam fatores que provocassem a vontade de jogar novamente.

\subsection{Aplicação do protótipo "Crayon Sharks"}

Para a aplicação do protótipo foi escolhida a Escola Municipal Professora Maura de Medeiros Bezerra, localizada na Rua das Dálias, S/N, no bairro COHAB, na Zona Rural da cidade de Macau/RN. A escola atende alunos de 1ㅇ ao 9o ano do ensino fundamental tanto do ensino regular quanto da EJA e funciona nos três turnos (matutino, vespertino e noturno), sendo o ensino regular durante a manhã e à tarde e a EJA durante a noite. A escola atende alunos da COHAB e das comunidades do Papagaio, Maxixe, Alcanorte, Salinópolis, Tambaú, Quixaba e Soledade. A escolha se deu, principalmente, em virtude de três fatores: à experiência que o autor obteve durante o Estágio Curricular Supervisionado realizado na escola; às boas relações entre a 
escola e o IFRN - Campus Macau, com a aceitação de estagiários do Curso de Licenciatura em Biologia; e à adequada estrutura física e organização pedagógica que a escola possui.

No dia 30 de maio de 2014 foi realizada uma visita à escola para apresentar o projeto e verificar a viabilidade da aplicação. Na secretaria, o Coordenador Pedagógico Sebastião Alves Maia concordou com a proposta e planejou a data e os horários para a aplicação. No dia agendado, 06 de junho de 2014, antes do início da aula, às 13h, foi entregue o plano de aula ao Coordenador e aos professores envolvidos e, na sala de vídeo, conforme planejado, foi dado início à aplicação do protótipo com a turma única do 70 ano do ensino fundamental. A aplicação teve como colaboradores a Professora de Ciências Aline da Silva Araújo de Aquino e o Professor de Inglês Robson Dantas de Lima. A turma em questão possuía 36 (trinta e seis) alunos matriculados que frequentavam regularmente as aulas, porém, no dia da aplicação, apenas 27 (vinte e sete) alunos estavam presentes.

A aula, com duração planejada para 02 (duas) horas-aula, foi iniciada às $13 \mathrm{~h} 50 \mathrm{~min}$, com uma metodologia expositiva e dialogada, com uma apresentação de slides, de maneira a abordar os principais conceitos de Ecologia, verificando o conhecimento prévio dos alunos em determinados assuntos, como: adaptação das espécies ao seu ambiente, relação entre presa e predador, conceito de biodiversidade, seleção natural e cadeias e teias alimentares. O diálogo, então, foi aberto com a turma e foram dados vários exemplos desses processos, despertando a curiosidade dos mesmos sobre o assunto.

No horário seguinte foi iniciada uma dinâmica em grupo com a aplicação do protótipo jogo digital educativo "Crayon Sharks", cujo processo de design encontra-se descrito no item 4.1. O jogo simula a vida de um tubarão em um recife de corais que deve se alimentar de determinadas espécies de peixe que dividem espaço num determinado ecossistema aquático. A contextualização do assunto relacionado à reprodução e descendentes ficou a cargo da narrativa e do diálogo com os alunos.

O material utilizado foi um notebook e um projetor, de maneira que as ações do jogador, que veria apenas a tela do notebook, fossem exibidas na projeção para os demais na sala. A dinâmica foi realizada da seguinte maneira: os alunos foram convidados a vir até a frente da sala, um de cada vez, e jogar três partidas do jogo, assumindo o papel dos tubarões e o restante da sala assumindo o papel dos peixes. Ao todo, 08 (oito) alunos utilizaram o jogo durante a dinâmica. 


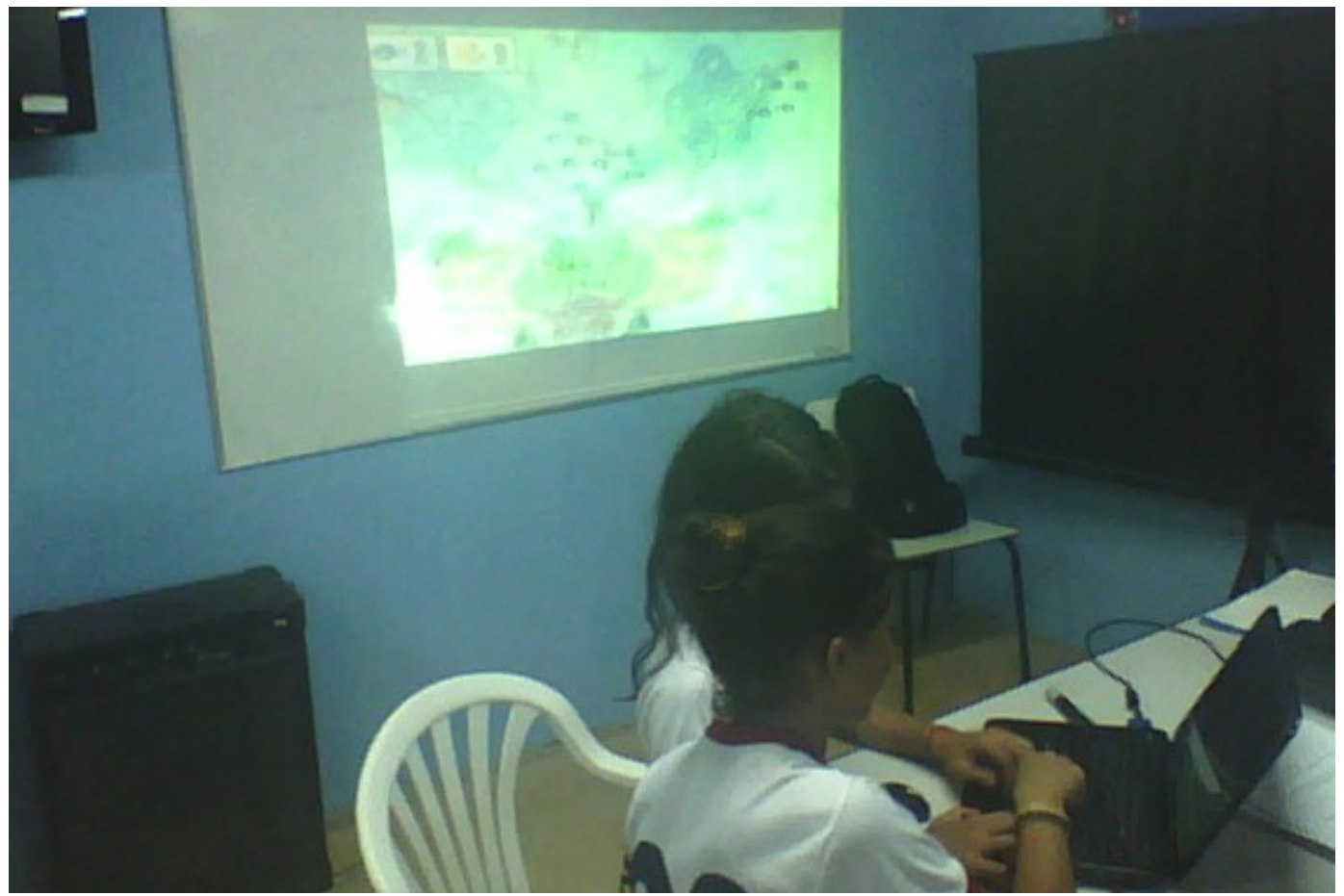

Figura 2: Alunas jogando em dupla após a dinâmica em grupo.

\section{RESULTADOS E DISCUSSÕES}

No final da aula, os vinte e sete alunos responderam um questionário semiestruturado, composto por quatro perguntas, para avaliar a experiência vivenciada na sala de aula com a aplicação do protótipo, concluída às $15 \mathrm{~h} 30 \mathrm{~min}$. Os dados obtidos a partir das respostas dos mesmos encontram-se relacionados e discutidos a seguir.

A primeira pergunta pedia que os alunos dissessem se o jogo digital apresentado durante a aula ajudava a entender melhor o assunto. Todos os alunos responderam que sim. Nos comentários feitos por eles no questionário é relevante destacar os seguintes "a gente nunca tem uma coisa dessas e foi bom" e "o jogo facilitou o meu aprendizado", mostrando que o professor necessita apresentar novidades atrativas aos alunos, que provoquem a curiosidade e os façam se interessar pelo assunto abordado. Sendo assim, foi possível perceber que a aceitação do jogo digital se deve, basicamente, à apresentação de uma aula diferente, com metodologias variadas e com o uso de uma tecnologia que faz parte do contexto social dos alunos.

Na segunda pergunta do questionário, foi solicitado que os alunos avaliassem o protótipo "Crayon Sharks" atribuindo notas com valores de 01 (um) - ruim/fraco - à 10 (dez) - ótimo/forte. Somando-se os valores das respostas de todos os alunos e dividindo-se o resultado pelo número total dos mesmos, a média obtida pelo protótipo foi 8 (oito), um resultado excelente para um protótipo. Analisando individualmente, foi possível observar que as notas atribuídas ao protótipo variaram entre 5 (cinco) e 10 (dez), conforme demonstrado no gráfico abaixo. 


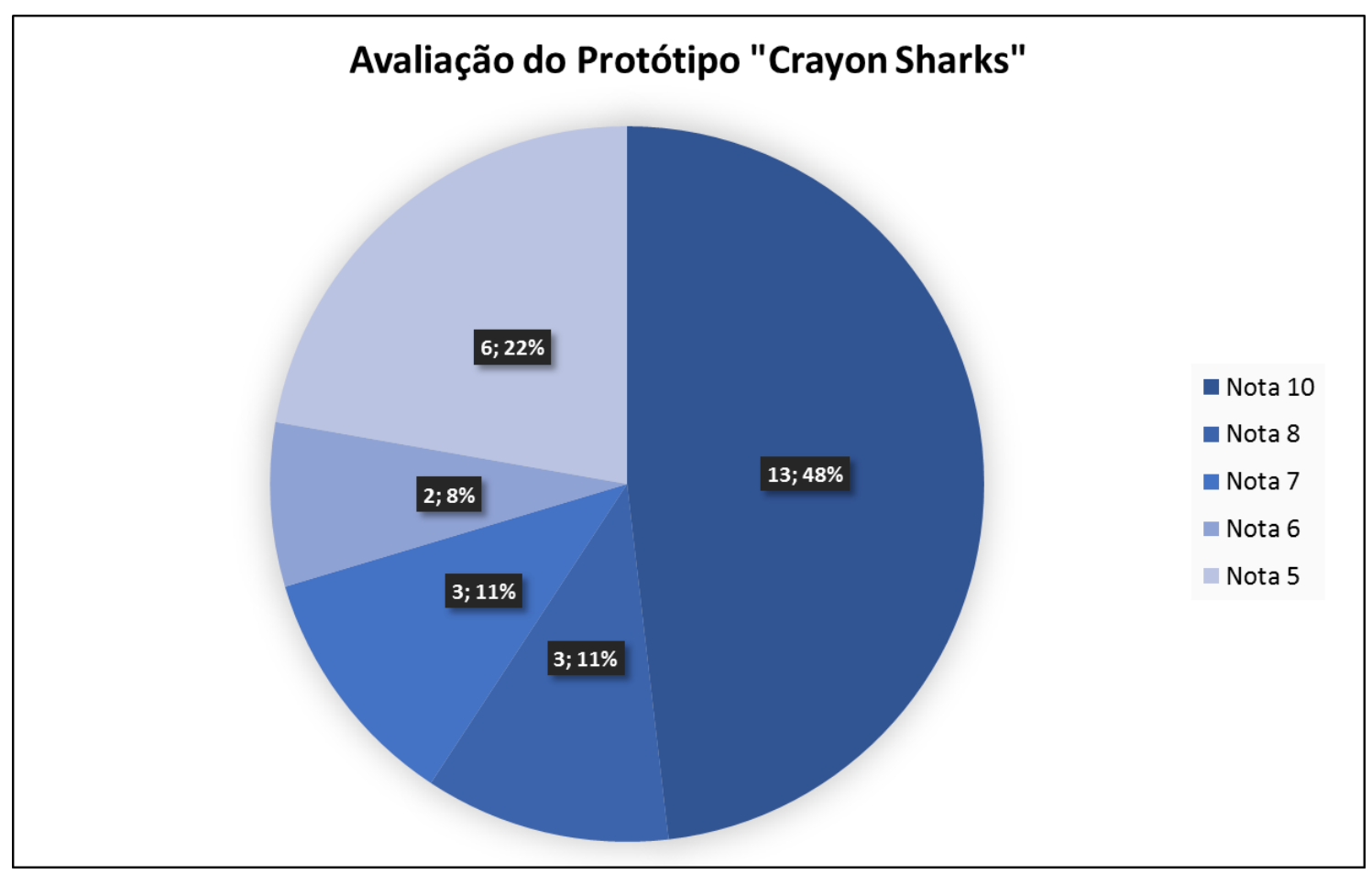

Figura 3: Gráfico sobre a avaliação do protótipo "Crayon Sharks".

$\mathrm{Na}$ terceira pergunta, os alunos precisavam responder se gostariam que outros professores utilizassem jogos digitais mais vezes em sala de aula e o porquê. Dos 27 (vinte e sete) alunos presentes, apenas 01 (um) respondeu que não gostaria que outros professores usassem essa prática por considerar jogos digitais "chatos e muito irritantes". Entre os comentários dos demais alunos são relevantes de destaque os seguintes: "a gente aprende e se diverte ao mesmo tempo", "assim fica mais fácil e divertido entender o assunto", "torna a aula mais divertida e os alunos se interessarão mais" e "nas aulas normais, é muita fala e pouca brincadeira".

A quarta e última pergunta do questionário pedia que os alunos dissessem se a dinâmica utilizada durante a aplicação do jogo digital tinha contribuído ou prejudicado o aprendizado do assunto. Todos os alunos responderam que a dinâmica contribuiu no aprendizado e alguns comentaram que todos puderam visualizar o jogo e aprender com a experiência dos colegas durante a partida. Entre os comentários relevantes destaco os seguintes: "o pessoal que jogou se divertiu e eu pude entender vendo eles jogarem" e "vários alunos tem vergonha de perguntar e, ao verem os outros participarem, perdem essa vergonha".

Como atividade avaliativa foi solicitado que os alunos desenhassem um esquema da teia alimentar representada no jogo digital, de acordo com as relações tróficas percebidas, identificando cada espécie com o nome em inglês, conforme proposta interdisciplinar planejada. 


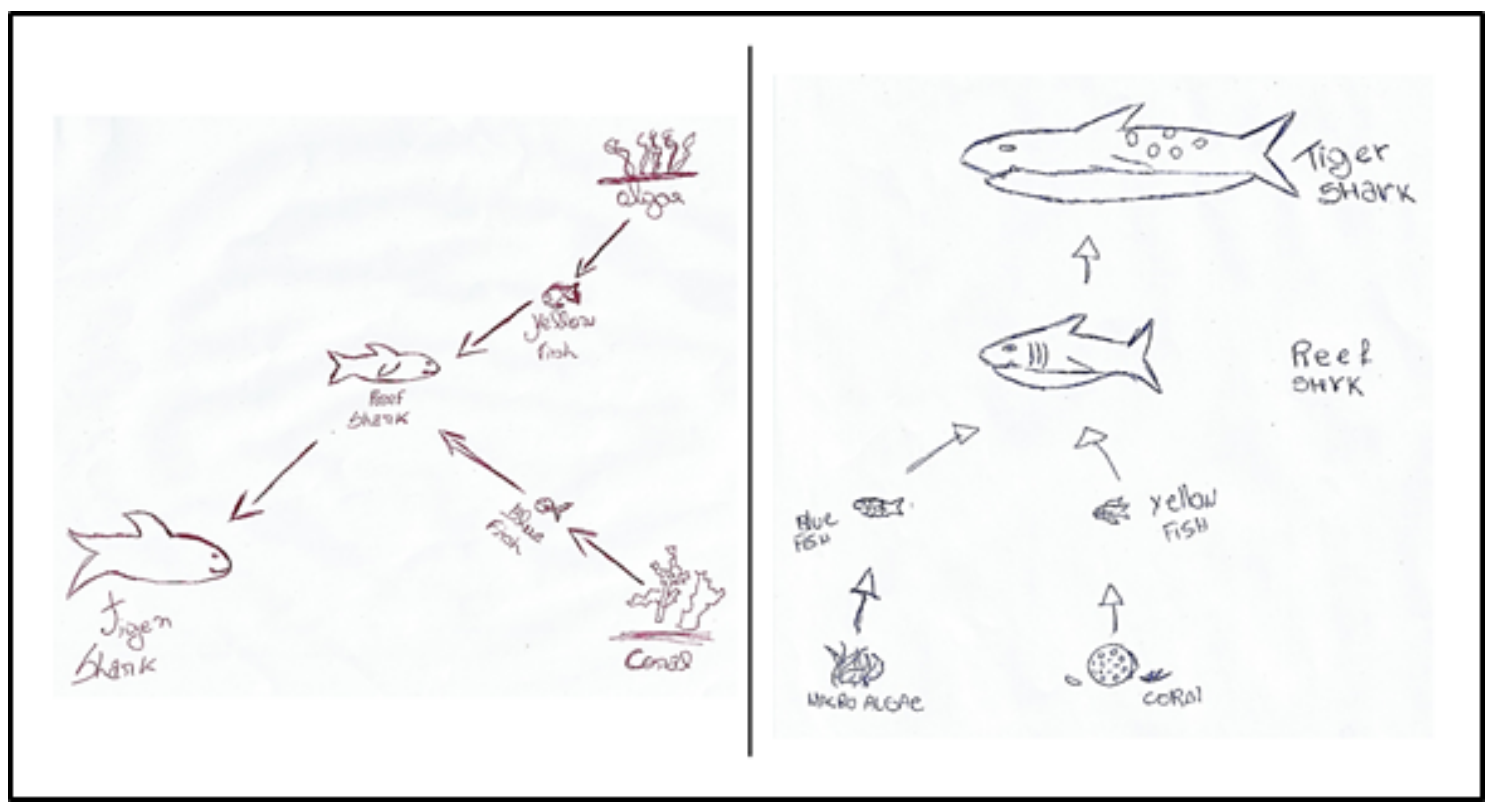

Figura 4: Exemplos da atividade complementar “teia alimentar do jogo “Crayon Sharks'”.

Com os resultados discutidos acima e a observação das reações de cada aluno durante a aula proposta foi possível constatar a aceitação da proposta por todos. 0 jogo foi caracterizado como uma experiência divertida que facilita ou estimula o aprendizado. Constatou-se, também, que o jogo desenvolvido conseguiu cumprir seu papel de mídia educacional, auxiliando a compreensão dos conceitos relacionados à disciplina de Ciências de uma maneira mais atrativa aos alunos.

Os resultados positivos são frutos do planejamento prévio, desde o processo de design até o método de aplicação. Por não se propor a substituir a metodologia tradicional e, também, não se limitando apenas a ela, a aplicação consegue mesclar o diálogo e a interação numa única proposta, dinamizando a exposição do conteúdo e propiciando um envolvimento dos alunos com o tema abordado.

Se levarmos em consideração que os resultados aqui apresentados foram obtidos a partir da aplicação planejada de um protótipo, podemos constatar o quão promissora é a ideia de se utilizar jogos digitais nas escolas e as possibilidades de aprendizado que essa experiência proporciona, tanto para os alunos quanto para os professores.

\section{CONCLUSÃO}

Além da transformação proporcionada pela popularização do uso da internet na Educação, o uso de novas mídias vem tornando a sala de aula, a cada dia, um ambiente de aprendizagem interativa. Tais mudanças trazem questionamentos sobre o papel do professor no uso e desenvolvimento de ferramentas midiáticas que auxiliem sua atuação em sala de aula no processo formativo dos alunos.

Os jogos digitais são mídias que possibilitam uma infinidade de aplicações e resultados quando utilizados em sala de aula. Tais potencialidades, se pensadas enquanto meios didáticos, não podem mais ser ignoradas pelos profissionais da educação. Portanto, é necessário que os professores usem essa mídia ao seu favor, se apropriando dos processos de aplicação e design, 
dialogando e atraindo a atenção dos alunos para a aula proposta, utilizando uma linguagem comum ao contexto social dos mesmos. A utilização de jogos digitais em sala de aula é uma ferramenta que, se bem aplicada, pode funcionar como um elo entre o lúdico e uma aprendizagem significativa.

Considerando os resultados obtidos com a mídia desenvolvida e relacionando-os ao fato de que a maioria dos alunos espera que o processo de ensino-aprendizagem exceda, algumas vezes, a didática tradicional, fica clara a necessidade da apresentação de novidades que "provoquem a atividade", estimulando a capacidade cognitiva dos mesmos e direcionando o ensino para atividades focadas na resolução de problemas, facilitando a vivência do conteúdo e viabilizando o envolvimento dos alunos com o tema proposto.

É válido ressaltar que o potencial da etapa de desenvolvimento de jogos digitais educativos não se limita apenas ao trabalho único do professor ou da sua equipe de desenvolvimento, porque ainda é possível se considerar possibilidades nas quais os próprios alunos sejam incluídos no processo criativo, auxiliando o professor em todas as etapas, fazendo com que todos experimentem um produto final desenvolvido por eles mesmos, aprofundando a relação professor-aluno e tornando-os construtores do próprio conhecimento.

\section{REFERÊNCIAS}

CAMPOS, M. C. R. M. A importância do jogo no processo de aprendizagem, 2006. In: MAURíclO, J. T. Aprender Brincando: O Lúdico na Aprendizagem. Disponível em: <http://www.profala.com/arteducesp140.htm>. Acesso em: 06 de janeiro de 2014.

CAMPOS, M. C. R. M. A importância do jogo no processo de aprendizagem. Disponível em: <http://www.psicopedagogia.com.br/entrevistas/entrevista.asp?entrlD=39>. Acesso em: 06 de janeiro de 2014.

COSTIKYAN, G. "I Have no Words \& I Must Design." In Interactive Fantasy 2. London: Hogshead Publishing, 1994.

COSTIKYAN, G. I Have No Words \& I Must Design: Toward a Critical Vocabulary for Games. Proceedings of Computer Games and Digital Cultures Conference, ed. Frans Mäyrä. Tampere: Tampere University Press, 2002.

CRAWFORD, C. Chris Crawford on Interactive Storytelling. $2^{\text {nd }}$ ed. Berkeley-CA: New Riders, 2013.

DELEUZE, G., GUATTARI, F. Mil Platôs: Capitalismo e Esquizofrenia Vol.1. 1ạ ed. São Paulo: Editora 34, 1995.

FREINET, C. A Educação pelo Trabalho. 1a ed. São Paulo: Martins Fontes, 1998.

FREIRE, P., SHOR, I. Medo e ousadia: o cotidiano dos professores. $2^{\underline{a}}$ ed. Rio de Janeiro: Paz e Terra, 1987.

FULLERTON, T. Game Design Workshop: a playcentric approach to creating innovative games. $2^{\text {nd }}$ ed. London: Elsevier, 2008.

GEE, J. P. What video games have to teach us about learning and literacy. New York: Palgrave Macmillan, 2004.

GREGORY, J. Game Engine Architecture. $1^{\text {st }}$ ed. Massachusetts: A K Peters, 2009. 
HUIZINGA, J. Homo Ludens: O Jogo como Elemento da Cultura. 4a ed. São Paulo: Perspectiva, 2000.

KLEINA, N. "O que é engine ou motor gráfico?". Publicado no site TecMundo em 22 de Março de 2011. Disponível em: <http://www.tecmundo.com.br/video-game/9263-o-que-e-engine-oumotor-grafico-.htm>. Acesso em: 10 de janeiro de 2014.

KLOPFER, E., OSTERWEIL, S., SALEN, K. Moving Learning Games Forward: Obstacles, Opportunities \& Openness. Cambridge-MA: The Education Arcade - MIT, 2009.

MACHADO, A. O sujeito na tela: modos de enunciação no cinema e no ciberespaço. São Paulo: Paulus, 2007, 250p.

McGONIGAL, J. Reality is Broken: Why Games Make Us Better and How They Can Change the World. $1^{\text {st }}$ ed. New York: Penguin Press, 2011.

MURRAY, J.H. Hamlet no holodeck: o futuro da narrativa no ciberespaço. São Paulo-SP: Itaú Cultural; UNESP, 2003.

NEMES, A. "4 programas que ajudam no desenvolvimento de games". Publicado no site TecMundo em 08 de Outubro de 2012. Disponível em: <http://www.tecmundo.com.br/ como-fazer/31025-4-programas-que-ajudam-no-desenvolvimento-de-games.htm>. Acesso em: 11 de janeiro de 2014.

PENDERSEN, R.E. Game Design Foundations. $1^{\text {st }}$ ed. Texas: Wordware Publishing, 2003.

SALEN, K., ZIMMERMAN, E. Rules of Play: Game Design Fundamentals. $1^{\text {st }}$ ed. London: MIT Press, 2004.

SCHELL, J. The Art of Game Design: A Book of Lenses. $1^{\text {st }}$ ed. Boston: Elsevier/ Morgan Kaufmann, 2008.

XAVIER, G. A condição eletrolúdica: Cultura visual nos jogos eletrônicos. 1a ed. Teresópolis-RJ: Novas Ideias, 2010. 